\title{
Selective turn-on fluorescence detection of cyanide in water using hydrophobic CdSe quantum dots $\dagger$
}

\author{
Angeles Touceda-Varela, Emily I. Stevenson, José A. Galve-Gasión, \\ David T. F. Dryden and Juan C. Mareque-Rivas* \\ Received (in Cambridge, UK) 19th October 2007, Accepted 11th February 2008 \\ First published as an Advance Article on the web 26th February 2008 \\ DOI: $10.1039 / b 716194 h$
}

\begin{abstract}
The ability of $2,2^{\prime}$-bipyridine-bound copper(II) ions to quench the photoluminescence of hydrophobic CdSe quantum dots is used to create a novel, selective turn-on fluorescence cyanide sensor.
\end{abstract}

The development of anion sensors that work in water is a challenging area of considerable current interest. ${ }^{1,2}$ Colloidal semiconductor nanocrystals (quantum dots, QDs) have attracted considerable attention in recent years. QDs have been shown to be useful for applications ranging from electronics and photonics to in vivo cellular imaging. ${ }^{3-6}$ Although some recent studies have shown that the photoluminescence of QDs is sensitive to the presence and type of ions close to the semiconductor core, ${ }^{7}$ so far there are very few QD-based anion sensors. ${ }^{7 h, i}$ One of the most common and readily available QD is CdSe protected with tri- $n$-octylphosphine oxide (TOPO). For ion sensing in water, however, the strategy has been to coat the semiconductor core with ligands capable of inducing ion recognition and water solubility. ${ }^{7}$ Often the design and synthesis of these ligands and the derivatization of the QD with them is time consuming, expensive and/or complicated, and in many cases, water-solubilization reduces the photoluminescence efficiency of the nanocrystal. Herein, we report a new approach to create effective fluorescence probes in water based on supramolecular complexes formed by mixing hydrophobic QDs with metal complexes and exploiting photoinduced electron transfer between them. ${ }^{8}$ Specifically, we have used the combination of TOPO-coated CdSe QDs, 2,2'-bipyridine(bipy) and $\mathrm{CuCl}_{2}$ (Scheme 1) as a turn-on fluorescence cyanide probe.

Hydrogen cyanide is a chemical warfare agent which affects the ability of cells to utilize oxygen. Although cyanide is extremely toxic $(0.5-3.5 \mathrm{mg}$ per $\mathrm{kg}$ of body weight are lethal to humans), it finds common industrial use in organic chemicals and polymers such as nitriles, nylon and acrylic plastics, fertilizer factories, precious metal mining and metal plating. ${ }^{9}$ As a result, there is considerable interest in finding readily available, simple-to-use and inexpensive methods to detect cyanide. ${ }^{10}$ Two recent studies by Sanz-Medel et al. have used water-soluble QDs as cyanide probes. ${ }^{7 h, i}$ Studies carried out on fire survivors and victims have shown blood cyanide levels

School of Chemistry, University of Edinburgh, Edinburgh, UK EH9 3JJ. E-mail: juan.mareque@ed.ac.uk; Fax:0131 6504743; Tel: 0131 6504761

$\dagger$ Electronic supplementary information (ESI) available: Details on experimental procedures and additional experimental data. See DOI: $10.1039 / \mathrm{b} 716194 \mathrm{~h}$ of $21.6 \pm 36.4 \mu \mathrm{M}$ in the survivors, and $116.4 \pm 89.6 \mu \mathrm{M}$ in the victims. $^{11}$

The TOPO-coated CdSe QDs used in this study were prepared following the literature procedure reported by Peng et al. ${ }^{12}$ The results reported below are based on CdSe QDs with the first absorption maximum at $574 \mathrm{~nm}$, and a maximum emission peak at $603 \mathrm{~nm}$ with excitation at $350 \mathrm{~nm}$, although similar results were obtained with QDs of other sizes (colours). The size of the nanocrystal was estimated to be $3.64 \mathrm{~nm}$ from the $574 \mathrm{~nm}$ first absorption peak. ${ }^{13}$ The QDs were dissolved in chloroform and mixed with 1:1 mixtures of bipy and $\mathrm{MCl}_{2}$ $(\mathrm{M}=\mathrm{Fe}, \mathrm{Zn}, \mathrm{Cu}, \mathrm{Co}$ and $\mathrm{Ni}$ ) in chloroform. The final QD concentration $(\sim 440 \mathrm{nM})$ was estimated from the size-dependant extinction coefficient of the first absorption peak. ${ }^{13}$ Bipy alone did not affect the fluorescence properties of the QDs, however, 1: 1 mixtures of this readily available chelating ligand and $\mathrm{MCl}_{2}$ changed the photoluminescence of the $\mathrm{CdSe}$ nanocrystals (Fig. 1). The $1: 1$ mixture of bipy and $\mathrm{CuCl}_{2}$, which affords [(bipy) $\left.\mathrm{CuCl}_{2}\right],{ }^{14}$ proved to be the most effective quencher (100\% quenching at $20 \mu \mathrm{M}$ concentration, Fig. 1).

The photoluminescence of QDs arises from the recombination of the electron-hole pair. It has been suggested that the interaction of molecules and ions with the surface atoms of the nanocrystal can affect the efficiency of this recombination, and several mechanisms have been proposed. ${ }^{7}$ Among the quenching mechanisms are inner filter effects, non-radiative
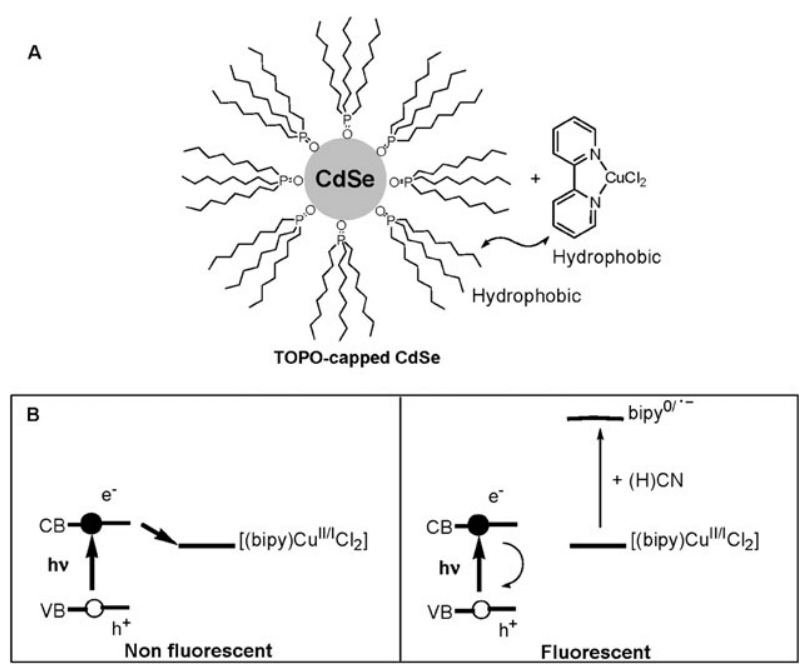

Scheme 1 Cyanide QD-based probe (A). Fluorescence quenching and cyanide sensing principle (B). 


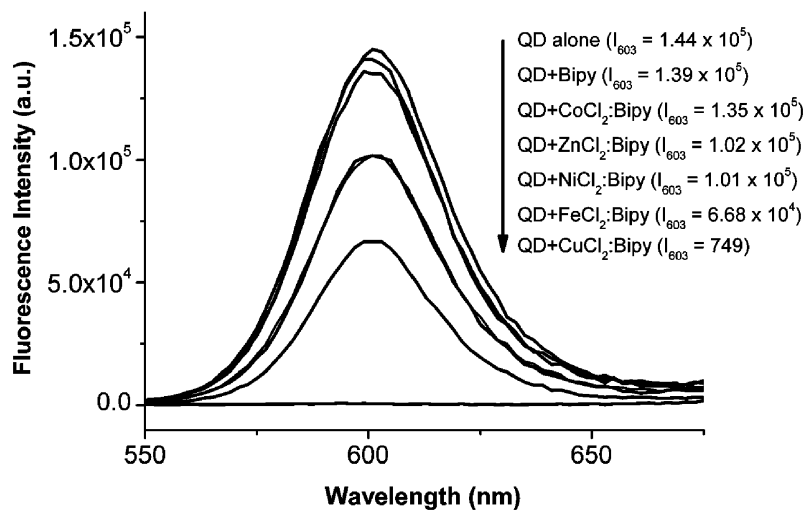

Fig. 1 Effect of 1: 1 mixtures of $\mathrm{MCl}_{2}$ and bipy $(20 \mu \mathrm{M})$ on the photoluminescence of TOPO-coated CdSe QDs ( $440 \mathrm{nM})$ in chloroform excited at $350 \mathrm{~nm}$.

recombination pathways and electron transfer processes, whereas enhancement of pholotuminescence has been attributed primarily to passivation of trap states in the surface. In this case, quenching of the QD photoluminescence is due to electron transfer between the QD and the complex. This is thermodynamically favorable because [(bipy) $\mathrm{CuCl}_{2}$ ] has the $\mathrm{Cu}^{\mathrm{II} / \mathrm{I}}$ reduction potential at $0.5 \mathrm{~V}$ vs. NHE (see Supplementary Information $\dagger$ ), which is well above the potential for the excited CdSe QDs $\left(\mathrm{ECB} \approx-1.0 \mathrm{~V} v s\right.$. NHE) ${ }^{15}$ This was confirmed by NMR studies (see Supplementary Information $\dagger)$. The ${ }^{1} \mathrm{H}$ NMR spectra of the QD : [(bipy) $\left.\mathrm{CuCl}_{2}\right]$ mixtures in $\mathrm{CDCl}_{3}$ did not have any signal in the 7-9 ppm region for the bipy protons due to coordination to the paramanetic $\mathrm{Cu}^{\mathrm{II}}$ ion. Upon irradiation at $350 \mathrm{~nm}$ for $2 \mathrm{~h}$, however, the characteristic bipy signals appeared suggesting the conversion to $\mathrm{Cu}^{\mathrm{I}}$. Concerning the approach of the complex to the nanoparticles, it is most likely facilitated by the ability of bipy to form hydrophobic interactions. ${ }^{16}$

Cyanide reacts with copper ions forming very stable $\left[\mathrm{Cu}(\mathrm{CN})_{n}\right]^{(n-1)-}$ species. ${ }^{17}$ This property has been exploited to remove copper ions from chelating pyridine-based ligands. ${ }^{18}$ Recently, we applied this concept to detect cyanide using self-assembled monolayers and electrochemical impedance spectroscopy. ${ }^{19}$ Addition of water (50 mM HEPES, $\mathrm{pH}$ 7.5) with $100 \mu \mathrm{M} \mathrm{CN}^{-}$to the chloroform solution containing the TOPO-coated $\mathrm{CdSe}$ QD and $20 \mu \mathrm{M}$ [(bipy) $\left.\mathrm{CuCl}_{2}\right]$ restored and blue-shifted (by $c a .10 \mathrm{~nm}$ ) the fluorescence of the QD (Fig. 2). ${ }^{20}$ IR studies of the evaporated chloroform solution showed a $\nu_{\mathrm{CN}}$ bands at 2124 and $2165 \mathrm{~cm}^{-1}$ (see Suplementary Information) characteristic of $\mathrm{CuCN}^{21}$ Thus, this sensor works by demetallation of the [(bipy) $\left.\mathrm{CuCl}_{2}\right]$ complex. Bipy, which has a reduction potential of $-2.0 \mathrm{~V} v s$. NHE (see Suplementary Information $\dagger$ ), is not able to quench the QD fluorescence. We investigated the effect of a wide range of other anions at $\mathrm{pH} 7.5$ (50 mM HEPES): $\mathrm{NO}_{3}{ }^{-}, \mathrm{AcO}^{-}, \mathrm{SO}_{4}{ }^{2-}$, $\mathrm{F}^{-}, \mathrm{Cl}^{-}, \mathrm{Br}^{-}, \mathrm{I}^{-}, \mathrm{ClO}_{4}{ }^{-}, \mathrm{HCO}_{3}{ }^{-}$and $\mathrm{H}_{2} \mathrm{PO}_{4}{ }^{-}$. Only cyanide turns on the fluorescence of the CdSe nanocrystals at neutral $\mathrm{pH}$. Thus, the copper-quenched CdSe nanocrystal is a probe with excellent selectivity for cyanide. Unlike any other currently existing cyanide sensor, this simple supramolecular construct provides an extremely simple fluorescent sensor for

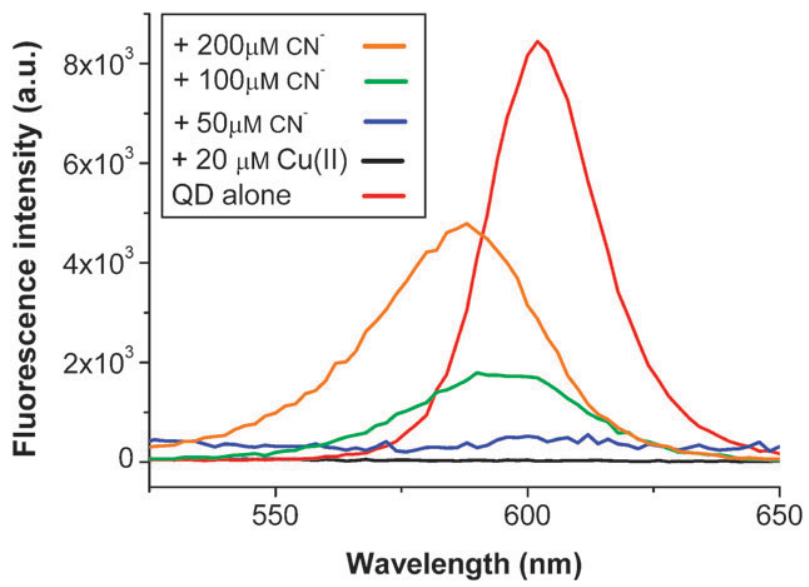

Fig. 2 Photoluminescence of the TOPO-coated CdSe QDs in chloroform ( $440 \mathrm{nM})$ after mixing with water (50 mM HEPES, $\mathrm{pH} 7.5$ ) (red line); water solutions (50 mM HEPES, pH 7.5) with $20 \mu \mathrm{M}$ [(bipy) $\mathrm{CuCl}_{2}$ ] (black line); water solutions (50 mM HEPES, $\mathrm{pH} 7.5$ ) with $20 \mu \mathrm{M}\left[(\right.$ bipy $\left.) \mathrm{CuCl}_{2}\right]$ and $50 \mu \mathrm{M} \mathrm{CN}^{-}$(blue line), $100 \mu \mathrm{M} \mathrm{CN}^{-}$ (green line) and $200 \mu \mathrm{M} \mathrm{CN}^{-}$(orange line).

the detection of the physiological safeguard level of cyanide $(20-100 \mu \mathrm{M})$ in water, and it works at physiological $\mathrm{pH}$ (i.e. it can be used to detect $\mathrm{HCN}_{(\mathrm{g})}$ ). In the two water-soluble QDbased cyanide sensors reported to date, ${ }^{7 h, i}$ cyanide turns off the photoluminescence of the CdSe core. In this case, however, the photoluminescence of the QD is turned on by cyanide, and as a result, the changes are clearly visible by the naked eye even after days (Fig. 3A). ${ }^{22}$

We explored to see if it is possible to avoid the use of toxic, volatile organic solvents like chloroform for $\mathrm{HCN}_{(\mathrm{g})}$ detection using this construct. Ideally, we wanted to find a very cheap, accessible and simple method. Polystyrene is a widely used economic polymer soluble in chloroform. Several recent reports have provided elegant methods for the incorporation of QDs onto the surface or inside polymer particles. ${ }^{23}$ Polystyrene (PS) was dissolved in a $440 \mathrm{nM}$ chloroform solution of the TOPO-coated CdSe QDs. Evaporation of the solvent produced a strongly fluorescent solid film which was stable for months (Fig. 3B, left). When the QD solution contained a $20 \mu \mathrm{M} \mathrm{1}: 1$ mixture of $\mathrm{CuCl}_{2}$ and bipy, the resulting film was

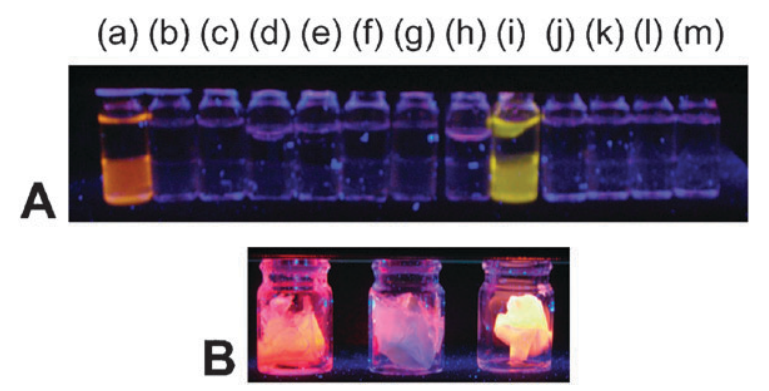

Fig. 3 Naked eye photoluminescence of TOPO-coated CdSe QDs in chloroform under a $365 \mathrm{~nm}$ lamp. A; without $\mathrm{CuCl}_{2}$ (a), with $20 \mu \mathrm{M}$ $\mathrm{CuCl}_{2}$ :bipy (b), with $20 \mu \mathrm{M} \mathrm{CuCl}_{2}$ :bipy and $100 \mu \mathrm{M} \mathrm{F}^{-}$(c), $\mathrm{Cl}^{-}$(d), $\mathrm{Br}^{-}$(e), $\mathrm{I}^{-}$(f), $\mathrm{ClO}_{4}^{-}$(g), $\mathrm{NO}_{3}^{-}$(h), $\mathrm{CN}^{-}$(i), $\mathrm{SO}_{4}{ }^{2-}$ (j), $\mathrm{AcO}^{-}(\mathrm{k})$, $\mathrm{H}_{2} \mathrm{PO}_{4}{ }^{-}$(l), $\mathrm{HCO}_{3}{ }^{-}$(m). B; PS/QD solid (left), $\mathrm{PS} / \mathrm{QD} / \mathrm{CuCl}_{2}$ :bipy solid after immersion in water (50 mM HEPES pH 7.5) (middle) and $100 \mu \mathrm{M} \mathrm{CN}^{-}$(50 mM HEPES pH 7.5) (right). 
not fluorescent even after immersion in water (50 mM HEPES, $\mathrm{pH}$ 7.5) for several weeks (Fig. 3B, middle). The copperquenched solid material was immersed into a water solution containing $100 \mu \mathrm{M} \mathrm{CN}^{-}$(50 mM HEPES, pH 7.5). Remarkably, after a period of 1-2 days the film showed fluorescence (Fig. 3B, right). The relatively long time required to observe fluorescence may be due to limited access of cyanide to the polymer-immobilized CdSe nanocrystals. However, this result demonstrates that it is possible to form a stable polystyrene QD-based fluorescent probe useful for environmental cyanide monitoring applications. This is another advantage of using water-insoluble QDs. Further studies to develop this proof-ofprinciple study are currently underway in this laboratory.

In summary, we have combined the ability of $\mathrm{CuCl}_{2}$ : bipy mixtures to quench the photoluminescence of TOPO-coated CdSe QDs in chloroform with the ability of $\mathrm{CN}^{-}$to bind and remove copper ions to create a novel, extremely simple and effective cyanide sensor. Detection of physiologically safeguard cyanide levels in water is achieved without making the QD water soluble. For the first time a QD probe turns on its fluorescence in the presence of anions. We are exploring several approaches to optimise this and related QD-based sensors for cyanide detection and to exploit the combination of QDs and metal complexes more widely.

This work was funded by The Leverhulme Trust. A.T.V. acknowledges the Xunta de Galicia (Spain) for a postdoctoral fellowship. We thank Prof. Xiaogang Peng and Grace L. Ong (University of Arkansas) for providing helpful QD synthetic information. We would like to thank Dr Wuzong Zhou and Ross Blackley at EaStCHEM-St. Andrews for the HRTEM studies.

\section{Notes and references}

1 Selected reviews: (a) P. D. Beer and P. A. Gale, Angew. Chem., Int. Ed. Engl., 2001, 40, 486; (b) R. Martínez-Mañez and F. Sancenon, Chem. Rev., 2003, 103, 4419; (c) J. L. Sessler and J. M. Davis, Acc. Chem. Res., 2001, 34, 989.

2 (a) L. O. Abouderbala, W. J. Belcher, M. G. Boutelle, P. J. Cragg, J. W. Steed, D. R. Turner and K. J. Wallace, Proc. Natl. Acad. Sci. USA, 2002, 99, 5001; (b) S. J. M. Koskela, T. M. Fyles and T. D. James, Chem. Commun., 2005, 945; (c) H. Miyaji, S. R. Collinson, I. Prokes and J. H. R. Tucker, Chem. Commun., 2003, 64; (d) A. Ojida, Y. Mito-oka, K. Sada and I. Hamachi, J. Am. Chem. Soc., 2004, 126, 2454; (e) D. H. Lee, S. Y. Kim and J.-I. Hong, Angew. Chem., Int. Ed. Engl., 2004, 43, 4777; (f) M. J. McDonough, A. J. Reynolds, W. Y. G. Lee and K. A. Jolliffe, Chem. Commun., 2006, 2971; (g) A. P. de Silva, G. D. McClean and S. Pagliari, Chem. Commun., 2003, 2010; (h) T. Gunnlaugsson, P. E. Kruger, P. Jensen, J. Tierney, H. D. P. Ali and G. M. Hussey, J. Org. Chem., 2005, 70, 10875.

3 V. L. Colvin, M. C. Schlamp and A. P. Alivisatos, Nature, 1994, $370,354$.

4 V. I. Klimov, A. A. Mikhailovsky, S. Xu, J. A. Hollingsworth, C. A. Leatherdale, H. J. Eisler and M. G. Bawendi, Science, 2000, $290,314$.

5 (a) M. Afzaal and P. J. O'Brien, J. Mater. Chem., 2006, 16, 1597; (b) M. Y. Odoi, N. I. Hammer, K. Sill, T. Emrick and M. D. Barnes, J. Am. Chem. Soc., 2006, 128, 3506.

6 X. Michalet, F. F. Pinaud, L. A. Bentolila, J. M. Tsay, S. Doose, J. J. Li, G. Sundaresan, A. M. Wu, S. S. Gambhir and S. Weiss, Science, 2005, 307, 538.

7 (a) Y. Chen and Z. Rosenzweig, Anal. Chem., 2002, 74, 5132; (b) K. M. Gattas-Asfura and R. M. Leblanc, Chem. Commun., 2003, 2684; (c) C. J. Murphy, Anal. Chem., 2002, 74, 520A; (d) C.-Y. Chen, C.-T. Cheng, C.-W. Lai, P.-W. Wu, K.-C. Wu, P.-T. Chou,
Y.-H. Chou and H.-T. Chiu, Chem. Commun., 2006, 263; (e) B Chen, Y. Yu, Z. Zhou and P. Zhong, Chem. Lett., 2004, 33, 1608; (f) B. Tang, J. Niu, C. Yu, L. Zhuo and J. Ge, Chem. Commun., 2005, 4184; (g) C. Xu and E. Bakker, Anal. Chem., 2007, 79, 3716; (h) W. J. Jin, M. T. Fernández-Argüelles, J. M. Costa-Fernandez, R. Pereiro and A. Sanz-Medel, Chem. Commun., 2005, 883; (i) W.J. Jin, J. M. Costa-Fernández, R. Pereiro and A. Sanz-Medel, Anal. Chim. Acta, 2004, 522, 1.

8 Photoinduced electron/hole and energy transfer processes between hydrophobic CdSe and $\mathrm{CdSe} / \mathrm{ZnS}$ core/shell QDs and metal complexes have been used for photochemical NO release and as light sensitizers for solar energy conversion. (a) M. Sykora, M. A. Petruska, J. Alstrum-Acevedo, I. Bezel, T. J. Meyer and V. I. Klimov, J. Am. Chem. Soc., 2006, 128, 9984; (b) D. Neuman, A. D. Ostrowski, R. O. Absalonson, G. F. Strouse and P. C. Ford, J. Am. Chem. Soc., 2007, 129, 4146.

9 (a) C. O. Ikediobi and L. M. Latinwo, Am. Environ. Lab., 1997, 9, 20; (b) Ulmann's Encyclopedia of Industrial Chemistry, Wiley-VCH, New York, 1999; (c) G. C. Miller and C. A. Pritsos, Cyanide Social, Industrial and Economic Aspects, in Proceedings of the TMS Annual Meeting, 2001, pp. 73-81.

10 (a) P. Anzenbacher, Jr, D. S. Tyson, K. Jursikova and F. N. Castellano, J. Am. Chem. Soc., 2002, 124, 6232; (b) R. Badugu, J. R. Lakowicz and C. D. Geddes, J. Am. Chem. Soc., 2005, 127, 3635; (c) J. V. Ros-Lis, R. Martínez-Mañez and J. Soto, Chem. Commun., 2005, 5260; (d) Y. G. Timofeyenki, J. J. Rosentreter and S. Mayo, Anal. Chem., 2007, 79, 251; (e) Y. H. Kim and J. I. Hong, Chem. Commun., 2002, 512.

11 F. J. Baud, P. Barriot, V. Toffis, B. Riou, E. Vicaut, Y. Lecarpentier, R. Bourdon, A. Astier and C. Bismuth, N. Eng. J. Med., 1991, 325, 1761.

12 L. Qu and X. Peng, J. Am. Chem. Soc., 2002, 124, 2049.

13 W. W. Yu, L. Qu, W. Guo and X. Peng, Chem. Mater., 2003, 15, 2854. The size determined in this way, and the crystallinity of the CdSe core was confirmed by electron microscopy (see Supplementary Information $\dagger$ ).

14 M. Hernández-Molina, J. González-Platas, C. Ruiz-Pérez, F. Lloret and M. Julve, Inorg. Chim. Acta, 1999, 284, 258.

15 I. Robel, V. Subramanian, M. Kuno and P. V. Kamat, J. Am. Chem. Soc., 2006, 128, 2385.

16 S. Balkumar, P. Thanasekaran, E. Rajkumar, K. J. Adaikalasamy, S. Rajagopal, R. Ramaraj, T. Rajendran, B. Manimaran and K.-L. Lu, Org. Biomol. Chem., 2006, 4, 352. In fact, $\mathrm{CuCl}_{2}$ (added in acetonitrile solutions for solubility reasons) was much less effective at quenching the fluorescence of the QDs despite its even higher $\mathrm{Cu}^{\mathrm{II} / \mathrm{I}}$ reduction potential $\left(E_{1 / 2}=1.24 \mathrm{~V} v s\right.$. NHE). We rule out coordination of the metal or bipy on the basis of not observing any paramagnetic shift of the TOPO-based proton resonances in QD : [(bipy) $\left.\mathrm{CuCl}_{2}\right]$ mixtures, nor line broadening of the bipy signals in QD : bipy mixtures.

17 K. Kurmia, D. E. Giles, P. M. May, P. Singh and G. T. Hefter, Talanta, 1996, 43, 2045.

18 (a) N. Solladie, j.-C. Chambron and J.-P. Savage, J. Am. Chem. Soc., 1999, 121, 3684; (b) N. Fujiwara, Y.-L. Liu, M. Takabashi and H. Kobayashi, J. Electrochem. Soc., 2006, 153, G394; (c) R. Rahimi and P. Hambright, J. Porphyrins Phthalocyanines, 1998, 2, 493.

19 V. Ganesh, M. P. Calatayud Sanz and J. C. Mareque-Rivas, Chem. Commun., 2007, 5010.

20 At physiological $\mathrm{pH}$ cyanide exists as $\mathrm{HCN}_{(\mathrm{g})}$ (the $\mathrm{p} K_{\mathrm{a}}$ of $\mathrm{HCN}_{(\mathrm{g})}$ is 9.21). At basic $\mathrm{pH}$, the $\mathrm{QD}$ : bipy : $\mathrm{CuCl}_{2}$ mixture becomes fluorescent (see Supplementary Information) but has the advantage that the cyanide detection limit is even lower $(20 \mu \mathrm{M}$ at $\mathrm{pH} 10)$.

21 G. A. Bowmaker, B. J. Kennedy and J. C. Reid, Inorg. Chem., 1998, 37, 3968.

22 We anticipate that the properties of the sensor for prolonged use and improved sensitivity will be enhanced by using other copperbinding ligands instead of bipy. However, an advantage of using bipy is that it is cheap and commercially available.

23 (a) Y. Lin, A. Böker, J. He, K. Sill, H. Xiang, C. Abetz, X. Li, J. Wang, T. Emrick, S. Long, Q. Wang, A. Balazs and T. P. Russell, Nature, 2005, 434, 55; (b) C.-P. Li, K.-H. Wei and J. Y. Huang, Angew. Chem. Int. Ed. Engl., 2006, 45, 1449; (c) W. Yin, H. Liu, M. Z. Yates, H. Du, F. Jiang, L. Guo and T. D. Krauss, Chem. Mater., 2007, 19, 2930; (d) P. O. O'Brien, S. S. Cummins, D. Darcy, A. Dearden, O. Masala, N. L. Pickett, S. Ryley and A. S. Sutherland, Chem. Commun., 2003, 2532. 